\title{
PRODUÇÃO DOS PROFESSORES DOS INSTITUTOS FEDERAIS DE EDUCAÇÃO, CIÊNCIA E TECNOLOGIA NO CURRÍCULO DA PLATAFORMA LATTES ${ }^{1}$
}

\section{PRODUCCIÓN DE PROFESORES INSTITUTO FEDERAL DE EDUCACIÓN, CIENCIA Y TECNOLOGÍA EN LA PLATAFORMA LATTES CURRICULUM}

\author{
Valmira Perucchi* \\ Suzana Pinheiro Machado Mueller**
}

\begin{abstract}
RESUMO:
Introdução: Os Institutos Federais de Educação, Ciência e Tecnologia foram criados para estimular a qualificação dos indivíduos em tecnologia e inovação e a produção de inovações tecnológicas. A escolha dos canais de comunicação utilizados por seus professores deve refletir essa intenção, uma vez que a produção bibliográfica e a produção tecnológica se utilizam de canais diferentes. Objetivo: Identificar e analisar quantitativamente as atividades de pesquisas realizadas pelos professores/pesquisadores dos Institutos Federais registradas em seus currículos Lattes, sob o ponto de vista da natureza doscanais utilizados em sua divulgação. Metodologia: Análise quantitativa realizada com técnicas bibliométricas. Resultados: Os resultados mostram que a produção bibliográfica supera quantitativamente a produção técnica, inovação, patentes e registros. Conclusões: A produção dos professores/pesquisadores não reflete com clareza a natureza voltada à tecnologia e inovação dos Institutos Federais.
\end{abstract}

\footnotetext{
${ }^{1}$ Este artigo é um desdobramento do projeto da tese: Produção de conhecimento científico e tecnológico nos Institutos Federais de Educação, Ciência e Tecnologia.

*Doutora em Ciência da Informação pelo Programa de Pós-Graduação em Ciência da Informação da Universidade de Brasília (UNB). E-mail vperucchi2@yahoo.com.br

** Doutora (PhD) em Information Studies pela University of Sheffield (Inglaterra, GB). Docente do Programa de Pós-Graduação em Ciência da Informação da Universidade de Brasília (UNB). E-mail mueller@unb.br
} 
Valmira Perucchi, Suzana Pinheiro Machado Mueller

Produção dos professores dos Institutos Federais de Educação, Ciência e Tecnologia no currículo da Plataforma Lattes

Palavras-chave: Institutos Federais de Educação Ciência e Tecnologia. Produção bibliográfica. Produção técnica. Produção em inovação. Produção em patentes e registros.

\section{INTRODUÇÃO}

Os Institutos Federais de Educação, Ciência e Tecnologia, conhecidos como Institutos Federais, foram criados pela Lei 11.892 em 29 de dezembro de 2008 a partir da transformação e/ou integração das antigas Escolas Agrotécnicas Federais, Escolas Técnicas e dos Centros Federais de Educação Tecnológica (CEFETs). As Escolas Técnicas Federais haviam sido criadas em 1959 e ofertavam ensino médio, técnico e profissionalizante. Em 1978, teve início a mudança das Escolas Técnicas para CEFETs, as quais, além de ofertarem ensino médio, técnico e profissionalizante, também passaram a formar engenheiros e tecnólogos por meio dos cursos tecnológicos em nível superior. As Escolas Agrotécnicas Federais criadas a partir de 1979 ofertavam ensino médio, técnico e profissionalizante voltados para a agropecuária.

De acordo com a Lei 11.892, no Art. 2, os Institutos Federais são instituições de "educação superior, básica e profissional, pluricurriculares e multicampi, especializados na oferta de educação profissional e tecnológica nas diferentes modalidades de ensino, com base na conjugação de conhecimentos técnicos e tecnológicos com as suas práticas pedagógicas [...]." O § 1 do Art. 2 da referida Lei estabelece que "para efeito da incidência das disposições que regem a regulação, avaliação e supervisão das instituições e dos cursos de educação superior, os Institutos Federais são equiparados às Universidades Federais." (BRASIL, 2008). Os Institutos Federais ofertam o ensino médio integrado que prepara os indivíduos para o exercício de profissões técnicas, ou seja, mão de obra qualificada para o mercado de trabalho. Ofertam também educação em nível de graduação em cursos superiores de tecnologia, licenciatura, bacharelado e engenharias, e em nível de pós-graduação. Os Institutos Federais, assim como as Universidades, além de possibilitarem a obtenção de conhecimentos pelo ensino, também devem produzir conhecimento e aplicá-los. 
Valmira Perucchi, Suzana Pinheiro Machado Mueller

Produção dos professores dos Institutos Federais de Educação, Ciência e Tecnologia no currículo da Plataforma Lattes

Com a criação dos Institutos Federais, o País pretendeu oferecer uma opção de ensino voltado de maneira mais direta para a qualificação dos indivíduos em tecnologia e inovação, mas sem negligenciar a ciência. No entanto, à primeira vista, seus objetivos, conforme dispostos na Lei que os criou, não os distinguem muito das tradicionais universidades, a não ser pela responsabilidade que continuam a ter em relação ao ensino médio; pois, tanto professores vinculados às universidades quanto aqueles vinculados aos Institutos Federais assumem responsabilidades com ensino, pesquisa e extensão. E todos estão sujeitos, para promoções, concessão de bolsas e auxílios, a avaliações que levam em consideração seu desempenho nessas três atividades.

Esta pesquisa pretende responder à seguinte pergunta: como os professores/pesquisadores dos Institutos Federais divulgam o conhecimento produzido? Tem como objetivo perceber se a intenção existente na justificativa da fundação dos Institutos Federais, uma opção de ensino voltado de maneira mais direta para a tecnologia e inovação, se reflete na escolha dos canais de divulgação da produção de conhecimento de seus professores, identificando quais canais são mais utilizados. A pesquisa pretende contribuir para um melhor entendimento da atuação dos Institutos Federais.

\section{COMUNICAÇÃO DA PRODUÇÃO DE CONHECIMENTO}

O conhecimento científico, para ser legitimado, deve ser divulgado, verificado e comprovado pelos pares. Esse processo ocorre tanto para a ciência quanto para a tecnologia. Comunicar o que foi produzido faz parte do desenvolvimento da ciência, da tecnologia e da inovação. Meadows (1999, p.7) afirma que "a comunicação se situa no próprio coração da ciência. É para ela tão vital quanto a própria pesquisa, pois a esta não cabe reivindicar com legitimidade este nome enquanto não houver sido analisada e aceita pelos pares." Ou seja, as atividades de pesquisa devem ser divulgadas.

A comunicação científica é, de acordo com Weitzel (2006, p. 87-88), “um processo que envolve a construção, comunicação e uso do conhecimento científico para possibilitar a promoção de sua evolução." Para que os 
Valmira Perucchi, Suzana Pinheiro Machado Mueller

Produção dos professores dos Institutos Federais de Educação, Ciência e Tecnologia no currículo da Plataforma Lattes

resultados de uma pesquisa sejam conhecidos, esses devem ser publicados. É através da comunicação do que foi produzido que se compartilham conhecimentos com a sociedade, ou seja, uma pesquisa só tem valor quando divulgada. A comunicação está presente em todas as atividades científicas e de pesquisa, por isso é necessário monitorar o que foi produzido e divulgado. Segundo Stumpf (2000, p.108), “a divulgação da pesquisa faz parte do conjunto de conhecimentos que se convencionou chamar de comunicação da ciência."

De acordo com Weitzel (2006, p.87), para que as atividades de comunicação "tenham condições de garantir sua eficiência [devem pressupor] também a publicação dos resultados das pesquisas em veículos de ampla audiência, acesso às informações científicas e apreensão do conhecimento registrado por outros cientistas para viabilizar o fomento de novos conhecimentos."

A produção de conhecimento, de acordo com Stumpf (2000, p. 107-108), é, "sem dúvida, uma das funções básicas das instituições acadêmicas." O processo de produção de conhecimento ocorre para que haja a descoberta e evolução do conhecimento. No entanto, para que essa descoberta e evolução ocorram, "o saber produzido precisa ser transmitido e divulgado a fim de que os resultados se tornem conhecidos e se incorporem ao conjunto das ciências."

A divulgação do que é produzido torna-se objeto de circulação de ideias. Meadows (1999, p.2) afirma que "o meio disponível e a natureza da comunidade científica afetam não só a forma como a informação é apresentada, mas também a quantidade de informação em circulação." O meio de circular essas ideias é através dos canais de comunicação científica. Para comunicar a produção em ciência, tecnologia e inovação, os pesquisadores têm, nos canais de comunicação, o elo que os liga ao seu público. Essa comunicação pode ocorrer por canais formais e informais. A comunicação formal ocorre, dentre outras formas, por meio de artigos publicados em periódicos, livro, capítulos de livros e anais de eventos. A comunicação informal ocorre, dentre outras formas, por meio de conversas entre os pesquisadores, 
Valmira Perucchi, Suzana Pinheiro Machado Mueller

Produção dos professores dos Institutos Federais de Educação, Ciência e Tecnologia no currículo da Plataforma Lattes

tecnólogos e seus pares. As redes de comunicação assim formadas são denominadas colégios invisíveis.

No entanto, ciência e tecnologia se utilizam de canais diferentes. Dentre os vários canais formais de comunicação científica, os mais utilizados para disseminar o que foi produzido é o artigo publicado em periódico científico referendado e dentre os canais para divulgar o conhecimento tecnológico está o depósito de patentes (FUJINO, 2006; GARCIA, 2006; WEITZEL, 2006). O artigo referendado registra e formaliza a autoria e prioridade científica, enquanto o registro da patente confere ao seu depositário direito comercial sobre a inovação tecnológica. Garcia (2006) confirma a utilização prioritária desses dois canais ao dizer que para disseminar o conhecimento produzido, "o maior percentual encontra-se divulgado em publicações científicas e outra parte disponibilizada em documentos de patentes".

A escolha de artigos para divulgar ciência, e de patentes para registrar tecnologia e inovação, é comentada por Moura e Caregnato (2011, p. 154), que afirmam que "para a análise da interação entre a produção oriunda das duas esferas, faz-se necessário considerar as diferenças e pontos em comum entre esses tipos de documentos, que se iniciam na fase de elaboração e vão até a sua divulgação".

O artigo científico e a patente são canais formais que têm em comum a avaliação pelos pares. $\mathrm{O}$ artigo é submetido a um periódico científico e é analisado por avaliadores, membros de seu corpo editorial ou especialistas especialmente designados. Ao publicar um artigo em revista referendada, o autor registra formalmente sua autoria, mas isso se refere aos conteúdos, não ao canal. Na maioria das revistas científicas produzidas por editores comerciais, os direitos autorais sobre o artigo publicado são geralmente cedidos pelo autor à revista. Nas revistas de acesso aberto, essa prática vem mudando. Por outro lado, o depósito de patentes segue um caminho diferente. As patentes submetidas ao Instituto Nacional da Propriedade Industrial (INPI) são primeiramente analisadas por técnicos desse Instituto. Quando concedida a patente, ela pertence a quem a solicitou. Para ser utilizada por terceiros, tem que ser comprada e sempre que for utilizada, devem-se pagar os royalties a 
Valmira Perucchi, Suzana Pinheiro Machado Mueller

Produção dos professores dos Institutos Federais de Educação, Ciência e Tecnologia no currículo da Plataforma Lattes

quem foi concedida a patente (FUJINO, 2006, p. 380; MOURA; CAREGNATO, 2011, p. 154-155).

Embora de maneira geral, como foi dito, ciência e tecnologia privilegiem principalmente o artigo científico e a patente, outras formas de divulgação como a publicação em anais de congressos, encontros científicos e técnicos de textos apresentados nessas reuniões, capítulos de livros, livros e relatórios técnicos são também bastantes utilizados. Além disso, as preferências variam bastante entre as diversas ciências, bem como entre ciência e tecnologia

A criação dos Institutos Federais tinha como motivação estimular não apenas a qualificação de técnicos, mas também a produção de inovações e novas tecnologias. Seria então de se supor que os professores e pesquisadores desses Institutos privilegiariam a divulgação de seus esforços de pesquisa por meio de produção técnica, inovação, patentes e registros em relação à produção bibliográfica. Esses termos são a terminologia utilizada pelo CNPq e são descritos mais adiante neste texto. O levantamento aqui relatado teve como um de seus objetivos verificar se esta suposição se confirma na realidade.

\section{PROCEDIMENTOS METODOLÓGICOS}

Existe um total de 38 Institutos Federais, situados nos 26 estados e no Distrito Federal, contemplando as cinco regiões do Brasil. O universo desta pesquisa são os professores desses 38 Institutos Federais. O número de professores dos 38 Institutos Federais e a lista com os seus nomes foram obtidos com a Coordenação Geral de Desenvolvimento de Pessoas da Rede Federal, órgão vinculado àSecretaria de Educação Profissional e Tecnológica (SETEC) que é vinculado ao Ministério da Educação (MEC). O pedido foi registrado no Sistema Eletrônico do Serviço de Informações ao Cidadão (e$\mathrm{SIC}$ ). A lista com os nomes dos professores foi utilizada exclusivamente para a busca do currículo na Plataforma Lattes do Conselho Nacional de Desenvolvimento Científico e Tecnológico (CNPq). A quantidade e a lista com os nomes dos professores dos 38 Institutos Federais foram disponibilizadas no e-SIC em 09 de dezembro de 2013. Constavam nesta data 24.335 professores 
Valmira Perucchi, Suzana Pinheiro Machado Mueller

Produção dos professores dos Institutos Federais de Educação, Ciência e Tecnologia no currículo da Plataforma Lattes

efetivos (em regime de trabalho de 20 horas, 40 horas e dedicação exclusiva) distribuídos pelos 38 Institutos Federais, como pode ser verificado na Tabela 1. Os professores efetivos que ingressaram posteriormente a esta data não foram incluídos nesta pesquisa. Dada a quantidade de professores nos 38 Institutos Federais, 24.335, foi necessário calcular uma amostra para a coleta dos dados nos currículos da Plataforma Lattes. Para uma pesquisa com as características que aqui se pretende, a amostra adequada deve ser do tipo aleatória simples. A amostra foi dividida proporcionalmente pelo quantitativo de professores efetivos dos 38 Institutos Federais.

A Tabela 1 está organizada em ordem alfabética pelo nome do órgão. Nela consta a quantidade de professores para cada Instituto Federal e a porcentagem de professores no Instituto Federal em relação ao universo e amostra (número de professores) correspondentes para cada Instituto Federal. Um artigo deve conter partes pré-textuais (título, autoria, resumo, palavraschaves), partes textuais (introdução, desenvolvimento desdobrado em subitens, e considerações finais apresentando a conclusão do estudo) e as partes póstextuais, que neste formato restringe-se às referências bibliográficas de obras citadas ao longo do texto.

Tabela 1 - Distribuição dos professores, porcentagem e amostra por Instituto Federal $(n=165)$

\begin{tabular}{|c|c|c|c|c|}
\hline Nome do Órgão & Sigla & $\begin{array}{c}\text { Quantidade de } \\
\text { Professores nos IF }\end{array}$ & $\%$ & Amostra \\
\hline Instituto Federal Baiano & IFBAIANO & 526 & 2,2 & 4 \\
\hline Instituto Federal Catarinense & IFC & 539 & 2,2 & 4 \\
\hline Instituto Federal da Bahia & IFBA & 1.225 & 5,0 & 8 \\
\hline Instituto Federal da Paraíba & IFPB & 891 & 3,7 & 6 \\
\hline Instituto Federal de Alagoas & IFAL & 741 & 3,0 & 5 \\
\hline Instituto Federal de Brasília & IFB & 331 & 1,4 & 2 \\
\hline Instituto Federal de Goiás & IFG & 867 & 3,6 & 6 \\
\hline Instituto Federal de Mato Grosso & IFMT & 767 & 3,2 & 5 \\
\hline Instituto Federal de Mato Grosso do Sul & IFMS & 229 & 1,0 & 2 \\
\hline Instituto Federal de Minas Gerais & IFMG & 548 & 2,2 & 4 \\
\hline Instituto Federal de Pernambuco & IFPE & 907 & 3,7 & 6 \\
\hline Instituto Federal de Rondônia & IFRO & 325 & 1,0 & 2 \\
\hline Instituto Federal de Roraima & IFRR & 221 & 0,9 & 1 \\
\hline Instituto Federal de Santa Catarina & IFSC & 925 & 3,8 & 6 \\
\hline Instituto Federal de São Paulo & IFSP & 1.163 & 4,8 & 8 \\
\hline Instituto Federal de Sergipe & IFS & 440 & 1,8 & 3 \\
\hline Instituto Federal do Acre & IFAC & 240 & 1,0 & 2 \\
\hline Instituto Federal do Amapá & IFAP & 108 & 0,4 & 1 \\
\hline Instituto Federal do Amazonas & IFAM & 586 & 2,4 & 4 \\
\hline Instituto Federal do Ceará & IFCE & 1.099 & 4,5 & 7 \\
\hline Instituto Federal do Espírito Santo & IFES & 1.134 & 4,7 & 8 \\
\hline Instituto Federal do Maranhão & IFMA & 1.167 & 4,8 & 8 \\
\hline Instituto Federal do Norte de Minas Gerais & IFNMG & 417 & 1,7 & 3 \\
\hline Instituto Federal do Pará & IFPA & 719 & 2,9 & 5 \\
\hline
\end{tabular}

Inf. Inf., Londrina, v. 22, n. 1, p. 111 - 128, jan./abr., 2017. http:www.uel.br/revistas/informacao/ 
Valmira Perucchi, Suzana Pinheiro Machado Mueller

Produção dos professores dos Institutos Federais de Educação, Ciência e Tecnologia no currículo da Plataforma Lattes

Instituto Federal do Paraná
Instituto Federal do Piauí
Instituto Federal do Rio de Janeiro
Instituto Federal do Rio Grande do Sul
Instituto Federal do Rio Grande do Norte
Instituto Federal do Sertão Pernambucano
Instituto Federal do Sudeste de Minas Gerais
Instituto Federal do Sul de Minas Gerais
Instituto Federal do Tocantins
Instituto Federal do Triângulo Mineiro
Instituto Federal Farroupilha
Instituto Federal Fluminense
Instituto Federal Goiano
Instituto Federal Sul Rio-Grandense

\begin{tabular}{|c|c|c|c|}
\hline IFPR & 680 & 2,8 & 5 \\
\hline IFPI & 754 & 3,1 & 5 \\
\hline IFRJ & 762 & 3,1 & 5 \\
\hline IFRS & 699 & 2,9 & 5 \\
\hline IFRN & 1.063 & 4,4 & 7 \\
\hline IFSERTÃO-PE & 352 & 1,4 & 2 \\
\hline IFSUDESTEMG & 482 & 2,0 & 3 \\
\hline IFSULDEMG & 358 & 1,5 & 2 \\
\hline IFTO & 463 & 1,9 & 3 \\
\hline IFTM & 335 & 1,4 & 2 \\
\hline IFFARROUPILHA & 426 & 1,7 & 3 \\
\hline IFF & 704 & 2,9 & 5 \\
\hline IFGOIANO & 383 & 1,6 & 3 \\
\hline IFSUL & 759 & 3,1 & 5 \\
\hline & 24.335 & 100,0 & 165 \\
\hline
\end{tabular}

Fonte: Elaborada de acordo com a quantidade dos professores dos 38 Institutos Federais disponibilizada no e-SIC, em 09 de dezembro de 2013, pela Coordenação Geral de Desenvolvimento de Pessoas da Rede Federal, órgão vinculado à SETEC/MEC.

O sorteio dos nomes dos professores para compor a amostra aleatória para cada Instituto Federal foi feito pelo Statistical Package for Social Sciences (SPSS), conforme lista anteriormente citada que foi disponibilizada pela SETEC no e-SIC.

Para a coleta dos dados nos currículos da Plataforma Lattes, foi elaborada no Excel uma planilha, a qual se trata do formulário utilizado. A primeira parte do formulário contém as características do próprio currículo, isto é, dados sobre a condição do currículo: sem currículo cadastrado; currículo desatualizado; currículo sem produção; currículo atualizado e com produção cadastrada. Esses itens tiveram que ser acrescentados ao formulário devido à quantidade de ocorrências desses casos. A inserção do currículo na Plataforma Lattes e a sua atualização constante são responsabilidade do pesquisador, especialmente os ligados às instituições de ensino superior, mas nem todos se cadastram ou os mantêm atualizados.

A segunda parte do formulário lista os diversos canais considerados para identificar a produção incluída em cada currículo examinado. Foram utilizados a terminologia eo agrupamento adotados pelo CNPq, os quais correspondem aos campos ou itens que os pesquisadores utilizam para cadastrar sua produção em seus currículos na Plataforma Lattes do CNPq. São eles:

- Produção bibliográfica: artigo completo publicado em periódicos; capítulo de livro; livro; trabalhos publicados em anais de eventos; apresentação 
Valmira Perucchi, Suzana Pinheiro Machado Mueller

Produção dos professores dos Institutos Federais de Educação, Ciência e Tecnologia no currículo da Plataforma Lattes

de trabalho e palestra; partitura musical; tradução; prefácio e posfácio e outra produção bibliográfica.

- Produção técnica: assessoria e consultoria; extensão tecnológica; programa de computador sem registro; produtos; processos ou técnicas; trabalhos técnicos; cartas, mapas ou similares; curso de curta duração ministrado; desenvolvimento de material didático ou instrucional; editoração; manutenção de obra artística; maquete; entrevistas, mesas-redondas, programas e comentários na mídia; relatório de pesquisa; redes sociais, websites e blogs e outra produção técnica.

- Inovação: patente; programa de computador registrado; cultivar protegida; cultivar registrada; desenho industrial registrado; marca registrada; topografia de circuito integrado registrado; programa de computador sem registro; produtos; processos ou técnicas; projetos de pesquisa; projetos de desenvolvimento tecnológico; projetos de extensão e outros projetos.

- Patentes e registros: patente; programa de computador registrado; cultivar protegida; cultivar registrada; desenho industrial registrado; marca registrada e topografia de circuito integrado registrado.

Os dados foram coletados dos currículos na Plataforma Lattes do CNPq, em seu site ${ }^{2}$, de forma manual, considerando o período de 2009 a 2014. Justifica-se esse período porque os Institutos Federais foram criados em 29 de dezembro de 2008. Analisar currículos Lattes é uma das técnicas mais usuais para se conhecer a produção de um pesquisador ou de uma instituição, pois fornecem dados referentes à formação, à atuação profissional e às atividades científicas, técnicas e de inovação de cada pesquisador. Foi realizado um levantamento preliminar para reconhecer que dados estariam disponíveis e outras condições que poderiam afetar a pesquisa. $\mathrm{O}$ dado nome dos professores/pesquisadores foi codificado da seguinte forma: IFBA1, IFBA2 e assim sucessivamente para todos os sujeitos da amostra e pertencentes a cada um dos 38 Institutos Federais.

${ }^{2}$ Site: http://buscatextual.cnpq.br/buscatextual/busca.do?metodo=apresentar 
Valmira Perucchi, Suzana Pinheiro Machado Mueller

Produção dos professores dos Institutos Federais de Educação, Ciência e Tecnologia no currículo da Plataforma Lattes

A coleta dos dados foi iniciada na segunda quinzena de fevereiro e finalizada na primeira quinzena de março de 2014. Coletamos os dados dos currículos atualizados em 2013 e 2014 (porque a busca no Lattes foi realizada em fevereiro e março de 2014) e com produção cadastrada. Currículos com atualizações anteriores a 2013 foram considerados desatualizados e descartados. Também não foram considerados os currículos atualizados, mas sem produção cadastrada.

\section{$4 \quad$ RESULTADOS DA PESQUISA}

Para a identificação e análise da produção bibliográfica, foram coletados dados relacionados a: artigos completos publicados em periódicos; capítulo de livro; livro; trabalhos publicados em anais de eventos; apresentação de trabalho e palestra e outra produção bibliográfica. Não foram encontrados dados para partitura musical; tradução; prefácio e posfácio. Os professores/pesquisadores inseriram nos seus currículos da Plataforma Lattes sob o rótulo outra produção bibliográfica os seguintes itens: dissertação; pôster; artigo publicado em site institucional; referenciais curriculares; resumo publicado em periódico; resenha e tradução.

PRODUÇÃO BIBLIOGRÁFICA: Dos 165 professores/pesquisadores da amostra, $88(53 \%)$ registraram alguma produção no item produção bibliográfica, enquanto $77(46,7 \%)$ não registraram nenhuma produção nesse item.

A Tabela 2 detalha os tipos de produção bibliográfica encontrados nos currículos Lattes desses 88 professores/pesquisadores. 
Valmira Perucchi, Suzana Pinheiro Machado Mueller

Produção dos professores dos Institutos Federais de Educação, Ciência e Tecnologia no currículo da Plataforma Lattes

Tabela 2 - Distribuição da produção bibliográfica cadastrada nos currículos da Plataforma Lattes dos professores/pesquisadores dos Institutos Federais $(\mathrm{n}=88)$

\begin{tabular}{l|l|l}
\hline \multicolumn{1}{c|}{ Produção bibliográfica } & \multicolumn{1}{c}{ Total } & \multicolumn{1}{c}{$\%$} \\
\hline Apresentação de trabalho & 306 & 45,07 \\
Trabalho publicado em anais de eventos & 180 & 26,51 \\
Artigo & 119 & 17,53 \\
Outra produção bibliográfica & 34 & 5,01 \\
Capítulo de livro & 28 & 4,12 \\
Livro & 12 & 1,77 \\
Total & $\mathbf{6 7 9}$ & $\mathbf{1 0 0 , 0 0}$ \\
\hline
\end{tabular}

Fonte: Elaboração de acordo com os dados obtidos nos currículos dos professores/pesquisadores dos Institutos Federais em fevereiro e março de 2014.

Como pode ser observado na Tabela 2, foi encontrado o total de 679 registros de produção bibliográfica. A frequência dos registros segundo o canal mostra uma típica curva de Bradford, com concentração em apresentação de trabalhos, publicação em anais de eventos e artigos. Sendo apresentação de trabalhos e publicação em eventos os dois canais mais usados, ambos informais, embora o segundo possa ser considerado mais formal que o primeiro, tal fato poderia ser interpretado como uma busca por troca de ideias com os pares (CRANE, 1975; MEADOWS, 1999).

A busca por troca de ideias entre os pares ocorre na maioria das vezes por meio dos colégios invisíveis. Crane (1975, p. 37) adaptou o conceito de colégios invisíveis para a comunicação científica informal, dizendo que "os cientistas, para se adaptarem ao problema da expansão de conhecimento nos seus campos, formam organizações sociais, os colégios invisíveis." A autora complementa que o cientista, muitas vezes, faz sozinho sua pesquisa, mas se nunca tiver oportunidade de discuti-la com alguém ou participar de uma rede de informação, ficará em má posição, pois tem que saber o que está se passando no seu campo para que a sua pesquisa produza impacto.

PRODUÇÃO TÉCNICA: Para a produção técnica, foram considerados os dados cadastrados nos currículos da Plataforma Lattes dos professores/pesquisadores dos Institutos Federais nos seguintes itens: assessoria e consultoria; programa de computador sem registro; produtos; curso de curta duração ministrado; desenvolvimento de material didático ou instrucional; entrevistas, mesas-redondas, programas e comentários na mídia; relatório de pesquisa; redes sociais, websites, blogs e outra produção técnica. 
Valmira Perucchi, Suzana Pinheiro Machado Mueller

Produção dos professores dos Institutos Federais de Educação, Ciência e Tecnologia no currículo da Plataforma Lattes

Os seguintes itens não tiveram ocorrências: extensão tecnológica; processos ou técnicas; cartas, mapas ou similares; editoração; manutenção de obra artística e maquete. Os professores cadastraram em seus currículos como outra produção técnica: curso de curta duração ministrado; palestra; mesaredonda e participação em comissão.

Houve registro de produção técnica nos currículos na Plataforma Lattes de 45 professores/pesquisadores $(27,2 \%)$ da amostra de 165 . Não foram encontrados registros em produção técnica nos restantes 120 currículos $(72,8 \%)$ da amostra de 165 professores/pesquisadores.

A Tabela 3 apresenta o quantitativo da amostra para a produção técnica cadastrada nos currículos da Plataforma Lattes dos 45 (27,2\%)professores/pesquisadores dos Institutos Federais que registraram produção nesse item.

Tabela 3 - Quantitativo da produção técnica cadastrada nos currículos da Plataforma Lattes dos professores/pesquisadores dos Institutos Federais $(n=45)$

\begin{tabular}{l|l|l}
\hline \multicolumn{1}{c|}{ Produção técnica } & \multicolumn{1}{c}{ Total } & \multicolumn{1}{c}{$\%$} \\
\hline Outra produção & 103 & 51,76 \\
Trabalhos técnicos & 65 & 32,66 \\
Programa de computador sem registro & 7 & 3,52 \\
Assessoria e consultoria & 5 & 2,51 \\
Desenvolvimento de material didático & 5 & 2,51 \\
Produto & 4 & 2,01 \\
Entrevistas, mesas-redondas & 4 & 2,01 \\
Cursos de curta duração & 3 & 1,51 \\
Relatório de pesquisa & 2 & 1,01 \\
Redes sociais, websites e blogs & 1 & 0,50 \\
Total & 199 & $\mathbf{1 0 0 , 0 0}$ \\
\hline
\end{tabular}

Fonte: Elaboração de acordo com os dados obtidos nos currículos dos professores/pesquisadores dos Institutos Federais em fevereiro e março de 2014.

Com relação aos tipos de produção técnica, foi encontrado um total de 199 registros. Dentre esses, os canais mais utilizados pelos professores/pesquisadores dos Institutos Federais são: outra produção técnica que corresponde a $51,76 \%$ e trabalhos técnicos $32,66 \%$. Chama a atenção o baixo número de ocorrências para quase todos os itens de produção técnica.

A própria natureza das atividades que podem resultar em produtos ou processos requer sigilo, e por isso não são, em geral, divulgadas pelo 
Valmira Perucchi, Suzana Pinheiro Machado Mueller

Produção dos professores dos Institutos Federais de Educação, Ciência e Tecnologia no currículo da Plataforma Lattes

pesquisador. Talvez isso ocorra com os professores/pesquisadores dos Institutos Federais, o que explicaria tão pouca produção técnica, como apresentado na Tabela 3. Conforme Moura e Caregnato (2011, p. 154), "a tecnologia é vista como uma atividade que objetiva criar artefatos." Neste caso, o pesquisador não pode divulgar a sua pesquisa até que tenha a garantia de proteção do que criou.

INOVAÇÃO: Para a produção dos professores/pesquisadores dos Institutos Federais referente à inovação, foram considerados: programa de computador registrado; projetos de pesquisa; projetos de desenvolvimento tecnológico; projetos de extensão. Desses, os seguintes não tiveram nenhuma ocorrência: patente; programa de computador sem registro; cultivar protegida; cultivar registrada; desenho industrial registrado; marca registrada; topografia de circuito integrado registrado; produtos; processos ou técnicas e outros projetos. Produção referente à inovação estava cadastrada nos currículos na Plataforma Lattes de 50 (30,3\%) professores/pesquisadores da amostra dos 165. Nenhum dado nessa categoria foi encontrado para os restantes 115 $(69,7 \%)$ dos indivíduos da amostra.

Foram contados projetos que tiveram início a partir de 2009. Considerando que um projeto leva em média dois anos para ser desenvolvido, foram incluídos na Tabela 4 projetos desenvolvidos e em desenvolvimento. A Tabela 4 mostra 0 quantitativo da produção em inovação dos professores/pesquisadores dos Institutos Federais cadastrada no currículo da Plataforma Lattes.

Tabela 4 - Quantitativo da produção em inovação dos professores dos Institutos Federais ( $n=50)$

\begin{tabular}{l|l|l}
\hline \multicolumn{1}{c|}{ Inovação } & \multicolumn{1}{c}{ Total } & \multicolumn{1}{c}{$\%$} \\
\hline Projeto de pesquisa & 110 & 62,50 \\
Projeto de extensão & 64 & 36,36 \\
Programa de computador registrado & 1 & 0,57 \\
Projeto de desenvolvimento tecnológico & 1 & 0,57 \\
Total & $\mathbf{1 7 6}$ & $\mathbf{1 0 0 , 0 0}$ \\
\hline Fonte: Elaboração de acordo com os dados obtidos nos currículos dos \\
professores/pesquisadores dos Institutos Federais em fevereiro e março de 2014.
\end{tabular}

Com relação aos tipos de produção em inovação, foi encontrado um total de 176 registros. Dentre esses tipos de produção em inovação, os mais recorrentes registrados pelos professores/pesquisadores dos Institutos 
Valmira Perucchi, Suzana Pinheiro Machado Mueller

Produção dos professores dos Institutos Federais de Educação, Ciência e Tecnologia no currículo da Plataforma Lattes

Federais são: projetos de pesquisa que equivalem a $62,50 \%$ e projetos de extensão $36,36 \%$. Para a produção em inovação, chama atenção a quantidade de itens que não tiveram nenhuma ocorrência.

PATENTES E REGISTROS: Foram considerados os seguintes itens para a produção de patentes e registros: patente; programa de computador registrado; cultivar protegida; cultivar registrada; desenho industrial registrado; marca registrada e topografia de circuito integrado registrado. Para nenhum desses itens houve ocorrência nos currículos da Plataforma Lattes. Tal resultado para patentes e registros está em consonância com o que dizem Jannuzzi e Souza (2008, p. 105) que "a patente ainda é pouco utilizada pela comunidade científica para publicação de suas pesquisas." Fujino (2006, p. 377) assevera que no caso brasileiro existe "baixo grau de aproveitamento de resultados de pesquisa na geração de patentes".

Como não foi encontrado nenhum registro de produção em patentes e registros nos currículos examinados, foi feita uma pesquisa na base de patentes do Instituto Nacional de Propriedade Industrial (INPI) na tentativa de confirmar ou complementar esse resultado. A busca na base de patentes do INPI foi realizada na primeira semana de julho de 2014 pelo nome dos 165 professores/pesquisadores da amostra, no campo 'nome do inventor', para verificar a existência de patentes publicadas a partir de 2009. Pesquisas posteriores à primeira semana de julho de 2014 podem apresentar resultados diferentes. Verificou-se que um dos 165 professores/pesquisadores de um dos Institutos Federais da Região Nordeste publicou duas patentes. Essas duas patentes foram depositadas em 2009, um ano após a formação dos Institutos. Uma dessas patentes não estava cadastrada no currículo desse professor e a outra patente estava cadastrada, mas como produto na produção técnica.

\section{COMENTÁRIOS FINAIS E CONCLUSÕES}

Os resultados do levantamento realizado chamam a atenção em vários aspectos. Primeiramente, se considerarmos dois grupos de produção: o primeiro, formado apenas pelos diversos itens de produção bibliográfica; e o 
Valmira Perucchi, Suzana Pinheiro Machado Mueller

Produção dos professores dos Institutos Federais de Educação, Ciência e Tecnologia no currículo da Plataforma Lattes

segundo, pelos itens listados sob produção técnica, inovação e patentes e registro de patentes, podemos verificar que o total de registros no grupo produção bibliográfica, 679 , é bem maior que a soma de registros encontrados nos outros três grupos, correspondendo a 375 registros.

Em segundo lugar, chama também a atenção o fato que tantos currículos da amostra não tenham apresentado nenhuma produção, em nenhum dos grupos. Pois de uma amostra aleatória de 165 professores de 38 instituições superiores equivalentes a universidades, apenas 88 (53\%), ou seja, pouco mais da metade, registraram em seus currículos Lattes alguma produção bibliográfica; e 50 (30,3\%), quase um terço, em inovação; e apenas 45 (27,2\%), ou seja, menos de um terço, registraram itens em produção técnica; e nenhum registro foi encontrado em patentes e registro de patentes. Considerando a natureza dos Institutos Federais, criados para estimular a produção de inovação, a baixa produção classificada como produção técnica, inovação e patentes em relação à produção bibliográfica realmente chama a atenção. Por outro lado, é preciso ter certa cautela na interpretação desses dados, uma vez que a modalidade de publicação bibliográfica mais frequente foi a apresentação de trabalho seguida de trabalho publicado em evento. Essas duas modalidades poderiam ser consideradas como preliminares tanto no que dizem respeito à produção de artigos científicos quanto à produção técnica e registro de patentes. Essa falta de clareza é uma limitação resultante da terminologia adotada pelo CNPq, que não permite a adição de novas modalidades. Também resultante dessa limitação, fica pouco claro o significado do item mais frequente registrado sob o rótulo produção técnica, outra produção, com o total de $51,76 \%$, pouco mais da metade de todos os itens nesse conjunto, seguido de trabalhos técnicos, também um rótulo genérico. Esses dois itens parecem ser o local, nos formulários do $\mathrm{CNPq}$, para registro de todas as atividades tecnológicas que não se enquadram nas demais. Esses fatos, acrescentados da pouca ocorrência de registros dos demais itens sob o rótulo produção técnica, sugerem que os rótulos de itens fixados pelo CNPq talvez não correspondam inteiramente à realidade das atividades e produção desses professores. 
Valmira Perucchi, Suzana Pinheiro Machado Mueller

Produção dos professores dos Institutos Federais de Educação, Ciência e Tecnologia no currículo da Plataforma Lattes

Examinando mais detalhadamente os dados sob inovação, verificamos que foram registrados quase tantos itens quanto sob produção tecnológica, 199 deste para 176 daqueles. Mas, de novo, a concentração se dá em poucos itens e de caráter genérico, projetos de pesquisa e projetos de extensão, sugerindo mais uma vez a falta de adequação dos formulários do CNPq.

Outro dado que merece menção é a ausência de registro de patentes no item existente para isso, patentes e registro de patentes, no currículo Lattes; fato corrigido em um caso com a busca nos registros do INPI, sugerindo, mais uma vez, que talvez o preenchimento dos currículos Lattes nem sempre é corretamente realizado.

Voltando à motivação inicial deste estudo e de acordo com os dados coletados, podemos concluir que os professores/pesquisadores dos Institutos Federais dão preferência à comunicação informal por meio de apresentações e também por meio da publicação de trabalhos em anais de eventos, duas modalidades que poderiam estar relacionadas. A produção de artigos científicos formalmente referendados também pode ser considerada significativa, pois é mais frequente que a modalidade das produções técnicas e de inovação. Esses resultados sugerem que, sob o ponto de vista da comunicação de suas atividades, os professores apresentam um perfil diferente daqueles das universidades, isto é, com predomínio de comunicações informais, mas quando a comunicação formal ocorre, os artigos científicos predominam, e não as patentes, registro de patentes ou inovação.

Professors' production of the federal institutes of education, science and technology in the curriculum of the lattes platform

\section{REFERÊNCIAS}

BRASIL. Lei $\mathbf{n}^{\circ}$. 11.892, de 29 de dezembro de 2008. Institui a Rede Federal de Educação Profissional, Científica e Tecnológica. Cria os Institutos Federais de Educação, Ciência e Tecnologia, e dá outras providências. Disponível em: $<$ http://www.planalto.ov.br/ccivil 03/Ato2007 2010/2008/Lei/L11892.htm. . . Acesso em: 23 jan. 2013.

CRANE, Diane. A natureza e o poder da comunicação científica. In: SOCIOLOGIA da ciência. Rio de Janeiro: FGV, 1975. p. 33-54. 
Valmira Perucchi, Suzana Pinheiro Machado Mueller

Produção dos professores dos Institutos Federais de Educação, Ciência e Tecnologia no currículo da Plataforma Lattes

FUJINO, Asa. Avaliação dos impactos da produção científica na produção tecnológica: perspectivas. In: POBLACION, Dinah Aguiar; WITTER, Geraldina Porto; SILVA, José Fernando Modesto da (Org.) Comunicação e produção científica: contexto e avaliação. São Paulo: Angellara, 2006. c. 14, p. 371-386.

GARCIA, Joana Coeli Ribeiro. Os paradoxos da patente. DataGramaZero - Revista de Ciência da Informação. v. 7, n. 5, out. 2006. Disponível em:<http://www.dgz.org.br/out06/Art 04.htm>. Acesso em: 13 maio 2013.

JANNUZZI, Anna H. L.; SOUZA, Cristina G. de. Patentes de invenção e artigos científicos: especificidades e similitudes. RBPG - Revista Brasileira de PósGraduação, Brasília, v. 5, n. 9, p. 03-125, dez. 2008.

MEADOWS, Arthur Jack. A comunicação científica. Brasília: Briquet Lemos, 1999.

MOURA, Ana Maria Mielniczuk de; CAREGNATO, Sonia Elisa. Coautoria em artigos e patentes: um estudo da interação entre a produção científica e tecnológica.

Perspectivas em Ciência da Informação, v.16, n.2, p.153-167, abr./jun. 2011.

STUMPF, Ida Regina C. A comunicação da ciência na universidade: o caso da UFRGS. In: MUELLER, Suzana P. M.; PASSOS, Edilenice J. L. (Orgs.).

Comunicação científica. Brasília: Departamento de Ciência da Informação UnB, 2000. p. 107-121.

WEITZEL, Simone da Rocha. Fluxo da informação científica. In: POBLACION, Dinah Aguiar; WITTER, Geraldina Porto; SILVA, José Fernando Modesto da (Org.) Comunicação e produção científica: contexto e avaliação. São Paulo: Angellara, 2006. c. 3, p. 81-114.

\title{
Title
}

Professors' production of the federal institutes of education, science and technology in the curriculum of the lattes platform

\begin{abstract}
:
Introduction: The Federal Institutes of Education, Science and Technology were created to stimulate the individuals' qualification in technology and innovation as well as the production of technological innovations. The choice of communication channels used by their professors should reflect this intention, since the bibliographic production and the technological production use different channels. Objective: To identify and quantitatively analyze the research activities carried out by the professors/researchers of the Federal Institutes registered in their Lattes curricula, considering the nature of the channels used in their dissemination. Methodology: Quantitative analysis performed by bibliometric techniques. Results: The results show that the bibliographic production exceeds quantitatively the technical production, innovation, patents and registers. Conclusions: The production of professors/researchers does not clearly reflect the nature of the technology and innovation of the Federal Institutes.
\end{abstract}

Keywords: Federal Institutes of Education, Science and Technology. Bibliographic production. Technical production. Production in innovation. Production in patents and registers.

Inf. Inf., Londrina, v. 22, n. 1, p. 111 - 128, jan./abr., 2017. http:www.uel.br/revistas/informacao/ 
Valmira Perucchi, Suzana Pinheiro Machado Mueller

Produção dos professores dos Institutos Federais de Educação, Ciência e Tecnologia no currículo da Plataforma Lattes

\section{Titulo}

Producción de profesores Instituto Federal de Educación, Ciencia y Tecnología en la plataforma lattes curriculum

\section{Resumen:}

Introducción: Los Institutos Federales de Educación, Ciencia y Tecnología han sido diseñados para estimular la cualificación de los individuos en la tecnología y la innovación y la producción de innovaciones tecnológicas. La elección de los canales de comunicación utilizados por sus profesores deben reflejar esa intención, ya que la tecnología de producción y la producción bibliográfica hacen uso de diferentes canales. Objetivo: Identificar y analizar cuantitativamente las actividades de investigación llevadas a cabo por los profesores/investigadores de los Institutos Federales registrados en su Lattes Currículo, desde el punto de vista de la naturaleza de los canales utilizados para su divulgación. Metodología: cuantitativa análisis realizado con técnicas bibliométricas. Resultados: Los resultados muestran que la producción bibliográfica supera cuantitativamente la producción técnica, la innovación, patentes y registros. Conclusiones: La producción de profesores/investigadores no refleja claramente la naturaleza enfocados en tecnología e innovación de los Institutos Federales.

Palabras clave: Institutos Federales de Educación y Tecnología de la Ciencia. Producción bibliográfica. Producción técnica. La innovación productiva. Producción de patentes y registros.

Recebido: 12.02 .2016

Aceito: 25.03 .2017 